University of Wollongong

Research Online

Faculty of Engineering and Information

Faculty of Engineering and Information

Sciences - Papers: Part B

Sciences

2017

The state of the art of battery charging infrastructure for electrical vehicles:

Topologies, power control strategies, and future trend

Viet Thang Tran

University of Wollongong, vtt595@uowmail.edu.au

Danny Sutanto

University of Wollongong, soetanto@uow.edu.au

Kashem M. Muttaqi

University of Wollongong, kashem@uow.edu.au

Follow this and additional works at: https://ro.uow.edu.au/eispapers1

Part of the Engineering Commons, and the Science and Technology Studies Commons

Research Online is the open access institutional repository for the University of Wollongong. For further information contact the UOW Library: research-pubs@uow.edu.au 


\title{
The state of the art of battery charging infrastructure for electrical vehicles: Topologies, power control strategies, and future trend
}

\author{
Abstract \\ Electric vehicle battery (EVB) charger topologies play a vital role to increase the penetration of EVs. This \\ paper reviews the status quo of EV battery (EVB) chargers in term of converter topologies, operation \\ modes, and power control strategies for EVs. EVB Chargers are classified based on their power levels and \\ power flow direction. Referring to power ratings, EV chargers can be divided into Level 1, Level 2 and Level \\ 3. Level 1 and Level 2 are normally compatible with on-board chargers while Level 3 is used for an off- \\ board charger. Unidirectional/bidirectional power flow can be obtained at all power levels. However, \\ bidirectional power flow is usually designed for Level 3 chargers as it can provide the huge benefit of \\ transferring power back to grid when needed. Moreover, the different operation modes of an EVB charger \\ are also presented. There are two main modes: Grid-to-Vehicle (V1G or G2V) and Vehicle-to-Grid (V2G). \\ The V2G mode helps bring EV batteries to become active distributed sources in smart grids and is the \\ crucial solution for a high EV penetration. Future trend and authors' recommendations with preliminary \\ simulation and experimental results are demonstrated in this paper.

\section{Disciplines} \\ Engineering | Science and Technology Studies

\section{Publication Details} \\ V. T. Tran, D. Sutanto \& K. M. Muttaqi, "The state of the art of battery charging infrastructure for electrical \\ vehicles: Topologies, power control strategies, and future trend," in 2017 Australasian Universities Power \\ Engineering Conference (AUPEC), 2017, pp. 1-6.
}

This conference paper is available at Research Online: https://ro.uow.edu.au/eispapers1/1699 


\title{
The State of The Art of Battery Charging Infrastructure for Electrical Vehicles: Topologies, Power Control Strategies, and Future Trend
}

\author{
Viet T. Tran, Student Member, IEEE, Danny Sutanto, Senior Member, IEEE, Kashem M. Muttaqi, \\ Senior Member, IEEE \\ School of Electrical, Computer and Telecommunications Engineering \\ University of Wollongong, New South Wales, Australia \\ vtt595@uowmail.edu.au,danny.sut@gmail.com,kashem@uow.edu.au
}

\begin{abstract}
Electric vehicle battery (EVB) charger topologies play a vital role to increase the penetration of EVs. This paper reviews the status quo of EV battery (EVB) chargers in term of converter topologies, operation modes, and power control strategies for EVs. EVB Chargers are classified based on their power levels and power flow direction. Referring to power ratings, EV chargers can be divided into Level 1, Level 2 and Level 3. Level 1 and Level 2 are normally compatible with onboard chargers while Level 3 is used for an off-board charger. Unidirectional/ bidirectional power flow can be obtained at all power levels. However, bidirectional power flow is usually designed for Level 3 chargers as it can provide the huge benefit of transferring power back to grid when needed. Moreover, the different operation modes of an EVB charger are also presented. There are two main modes: Grid-to-Vehicle (V1G or G2V) and Vehicle-to-Grid (V2G). The V2G mode helps bring EV batteries to become active distributed sources in smart grids and is the crucial solution for a high EV penetration. Future trend and authors' recommendations with preliminary simulation and experimental results are demonstrated in this paper.
\end{abstract}

Index Terms-Electric vehicle battery (EVB), EV chargers, photovoltaic (PV) generation.

\section{INTRODUCTION}

Pure electric vehicles are becoming an emerging technology in the transportation and power sector because of their zero-emissions [1]. EVs have been enhanced significantly to allow for a long driving range using novel battery technologies and fast charging stations. The high penetration of EVs at the grid point of common coupling (PCC) brings feasible solutions for utilizing EV batteries to stabilize the grid such as active/reactive power control, PCC voltage and frequency control, or mitigation of the output fluctuation of renewable energy sources, [2-4]. However, high EV penetration has not been achieved because of several critical barriers such as the high cost of batteries, limited charging/discharging cycles, and the shortage of public charging stations with fast charging facilities. The use of fast chargers can result in an unstable grid as the charging loads can rapidly increase/decrease in an unpredictable manner. The high power switching converters used in EV chargers can also produce unwanted harmonics on distribution systems [5]. Based on the power ratings, the EV chargers can be divided into Level 1, Level 2 and Level 3. Level 1 and Level 2 are typically designed for home charging and public charging stations with power less than $2 \mathrm{~kW}$ of the Level 1 and around $20 \mathrm{~kW}$ of the Level 2 [6]. They are designed to comply with the standard for $120 / 230 \mathrm{~V}$ distribution grid voltage level. The adapter both for the charger and the EV charging plug typically comply with the SAE J1772 standard [7]. Level 3 is for fast chargers used in commercial charging stations. They are normally connected directly to the medium voltage three phase systems. Level 3 chargers are designed for a fast charging using DC with power rating around $100 \mathrm{~kW}$ with charging time is less than 30 minutes. The DC fast charging standards are presented in [7], [8].

$\mathrm{EV}$ battery chargers can be integrated in an EV as an onboard charger or separated as an off-board charger. The power flows between EV batteries and the grid can be unidirectional or bidirectional. The unidirectional power flow is implemented in all recent commercial on-board chargers because of the simplicity, and reliability in their topologies and control. Bidirectional chargers can be controlled to inject the EV battery power into the grid. With the bidirectional functionality, an EV battery can be considered as an active distributed source with several operation modes. This can help to stabilize the grid at peak demand [9-11]. Even though bidirectional chargers have not been widely commercialized yet, they have received increasing interest from researchers as they can provide a promising solution for future EVs.

This paper presents a review of recent battery charging infrastructure for EVs in term of converter topologies, power 
control strategies, and future trends as follows: Section II shows an overview of the various topologies of EV battery charger. Brief summary strategies for power control and EV battery charging with selective topologies are shown in Section III and Section IV. Future trends with recommendations and conclusion are given in the Sections $\mathrm{V}$ and VI.

\section{EV BATTERY CHARGER TOPOLOGIES}

In general, EV battery chargers are designed based on fundamental $\mathrm{DC}$ of $\mathrm{AC}$ power converters which must have a high power density, high efficiency. DC/DC converters are typically Buck/ Boost or switch-mode converters, AC/DC converters are based on uncontrolled or controlled rectifiers. $\mathrm{DC} / \mathrm{AC}$ converters are usually based on H-bridge inverters for single phase or three- leg inverters for a three phase system. The charging/ discharging algorithms are implemented digitally using high performance processor or a field-programmable gate array (FPGA). Fig. 1 shows the general configuration of an EV charging system. Each type of the power converters used in Fig. 1(which are numbered from number 1 to number 6) will be discussed in detail.

EV batteries can be either charged by an on-board charger (Level 1,2) or by an off-board charger (Level 3). As can be seen in Fig. 1, all on/off-board chargers contain AC/DC converters and DC/DC converters. However, the topologies and the power rating of the converters in of each type of the chargers are totally different. A unidirectional on-board EV battery charger for Level 1 and Level 2 is illustrated in Fig. 2 [12], in which the AC/DC converter (labelled 1) consists of an $\mathrm{H}$-bridge diode rectifier and an interleaved DC/DC Boost converter. This converter is controlled to attain a high power factor correction (PFC).

The DC/DC converter (labelled 3 in Fig. 1) is an H-bridge LLC-resonant converter. This converter has high efficiency as it can operate at wide load ranges with zero-voltage switching (ZVS) [10].

Another Boost PFC topology is presented in [13]. The converter eliminates the need of the H-bridge rectifier input while still maintaining a boost topology, which can reduce the heat problem; however, this converter produces electromagnetic interference (EMI). It can be observed from Fig. 2 that there are a variety of different charger topologies that can be proposed by changing the components of AC/DC converter (labelled 1) and DC/DC converter (labelled 3). For example, the authors in [14] use a SEPIC PFC to replace the interleaved boost PFC in the $\mathrm{AC} / \mathrm{DC}$ converter (labelled 1) to improve the efficiency of the LLC stage. This converter provides an ultra-wide range for the DC link voltage, and is always controlled to operate at the near the resonant frequency. References [11] and [15] proposed a bidirectional on-board Level 1 and Level 2 charger. As can be seen in Fig. 3 , the authors use an H-bridge boost converter as a $\mathrm{AC} / \mathrm{DC}$ converter (labelled 1) and a bidirectional Buck/Boost converter for a DC/DC converter (labelled 3). This configuration not only can control the EV battery charging current, but also can produce reactive power inject to the grid in order to support grid ancillary services.

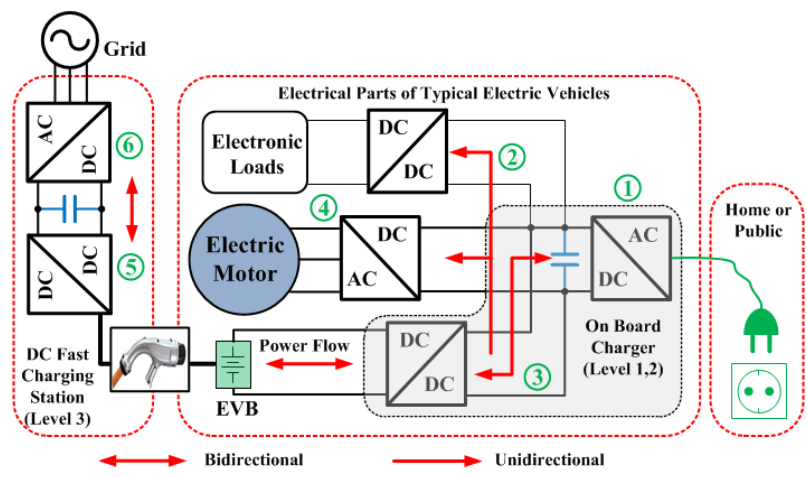

Fig. 1. General configuration of an EV charging system.

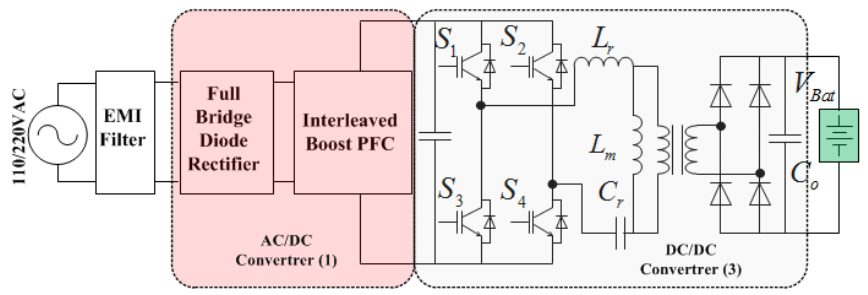

Fig. 2. A typical topology of an on-board charger with unidirectional power flow [12], [16]

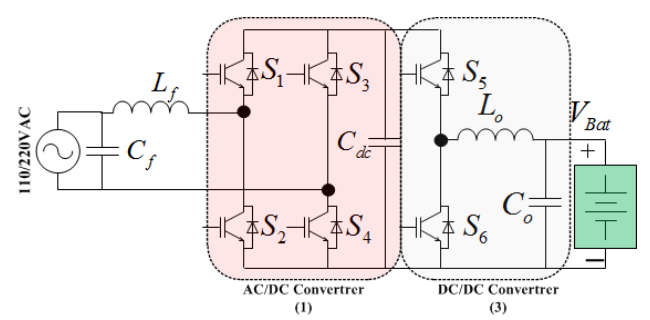

Fig. 3. A typical topology of an on-board charger with bidirectional power flow, as in [11],[15].

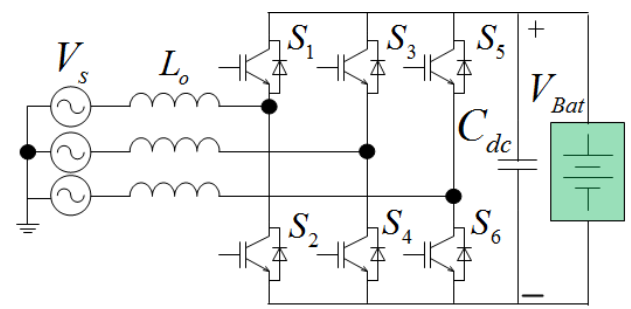

Fig. 4. A bidirectional on-board charger for Level 3, as in [2]

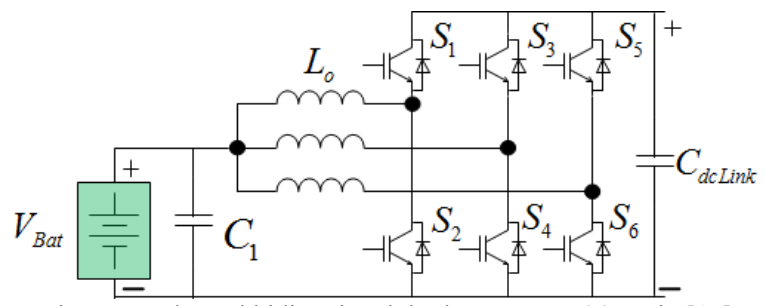

Fig. 5. Interleaved bidirectional dc-dc converter (5), as in [17] 
A Level 3 off-board fast charging topology are presented in [2], as shown in Fig. 4. The topology uses a three phase $\mathrm{AC} / \mathrm{DC}$ Boost rectifier for the PFC charging operation, and reactive power operation. However, this topology is only suitable if the DC voltage of the EV battery $V_{b a t}$ is higher than $V_{d c}$. When the battery $V_{b a t}$ is less than $V_{d c}$, a DC/DC converter is required. This converter can be implemented using a single or interleaved bidirectional Buck/Boost converter [18], [17].

Multilevel converters as shown in Fig. 6 (a) can be the best candidate topology for Level $3 \mathrm{EV}$ chargers as it can achieve a high power density while reducing the stress on the power switching devices. These converters provide a good power quality at the PCC with less harmonic currents [19]. DC/DC converters with a three-level output voltage have also been studied in $[19,20]$, as can be seen in Fig. 6 (b). This converter has a high power density, and it is currently the best candidate for DC fast chargers. However, the control of this converter at high power, high frequency is more complex and the computation of the control algorithm needs a high speed DSP or FPGA as normally the space vector modulation is required. Table I shows the summary of the power converters that have been proposed or used in an EV battery charger.

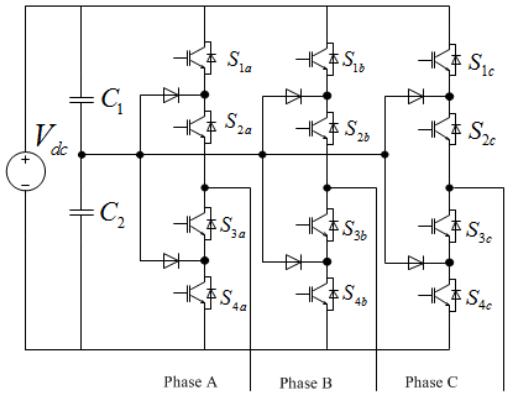

a)

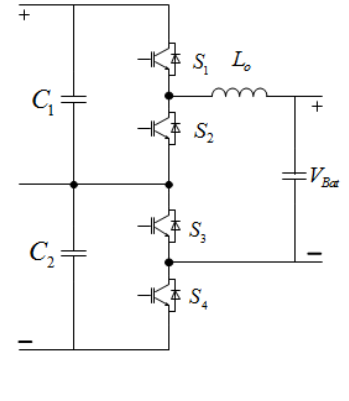

b)
Fig. 6. a) Three-level diode-clamped converter (6), as in [19], and b) Three Level dc-dc Converter (5), as in [19, 20].

TABLE I

POSSIBILITY OF CONVERTER TOPOLOGIES FOR EV CHARGER

\begin{tabular}{l|l}
\hline \multicolumn{1}{c}{ Converter } & \multicolumn{1}{c}{ Topologies } \\
\hline AC/DC converter (1) & Half-Bridge, Full-Bridge \\
\hline DC/DC converter (2) & Buck converter \\
\hline DC/DC converter (3) & $\begin{array}{l}\text { Bidirectional (interleaved) Buck/Boost } \\
\text { Converter }\end{array}$ \\
\hline DC/AC converter (4) & 3 phase 2 level/3 level inverters \\
\hline DC/DC converter (5) & $\begin{array}{l}\text { Bidirectional (interleaved) Buck/Boost } \\
\text { Converter, multilevel dc-dc Converter }\end{array}$ \\
\hline DC/DC converter (6) & 3 phase-3 level converters \\
\hline
\end{tabular}

\section{Power CONTROL STRATEGY}

The energy exchanges between the EVs and the electric grid can be unidirectional or bidirectional, as shown in Fig.1. Unidirectional power flow chargers use an uncontrolled rectifier connected to a DC/DC converter [12]. Fig. 2 shows a typical topology for a unidirectional power flow charger using a resonant converter connected with a full-bridge in series. A simple current control will be utilized to control the EV charging current. Due to the one direction for the power flow, the grid operator can forecast and therefore manage peak demand at the peak time when a high EV penetration gets charged at the same time. For a bidirectional power flow charger, $\mathrm{AC} / \mathrm{DC}$ converter is a controlled H-bridge or an active three phase converter while DC/DC converter is bidirectional as shown in Fig. 3, Fig. 4 and Fig. 5. The controllers are more complex with both current and voltage control using PI control. Other control methods such as adaptive control, fuzzy logic, sliding mode control or predictive control can be applied for bidirectional $\mathrm{EV}$ chargers.

With bidirectional power flow, two operation modes of the EV battery chargers are defined as grid-to-vehicle (V1G or G2V), vehicle-to-grid (V2G) [10]. The V2G mode helps bring $\mathrm{EV}$ battery become an active distributed resource to make the future grid more stable and smarter.

The concept of G2V is natural as EVs are normally charged from the grid. This concept can be extended for renewable energies such as solar photovoltaic $(\mathrm{PV})$ or wind energy, EVs can be charged from the renewable energies to minimize the charged energy from the grid. However, due to the considerable capacity of the EV batteries, it is possible to utilize EV battery to help stabilize the power grid during peak demand as back-up energy storage system. This action using bidirectional battery chargers is defined as V2G [2], [11], and [18]. In addition, this operation mode can be used to support a high penetration of solar PV as EV battery can be utilized as a buffer energy unit (BEU) to smooth the power fluctuation of solar PV output generation [21].

\section{Charging Strategies}

It is well-known that a large-scale of EV penetration can have severe impacts on the distribution grid such as the overheat of distribution transformers; voltage fluctuations, harmonic distortion $[5,22,23]$. To deal with aforementioned issues, in the long term there additional upgrade for the grid infrastructure will be required. For the short term, controlled charging schemes should be applied [24]. There are two charging strategies: uncoordinated strategy and coordinated strategy. Uncoordinated strategy is natural when the EV owners will charge the EV battery immediately after they get home or randomly charge the car from the home power outlet [25]. Uncoordinated charging causes the local load to increase rapidly at peak demand. This results in extra power losses on over-loaded distribution transformers and cables.

Coordinated charging strategies are the solution to eliminate the effects of high EV penetration on the grid by optimizing the charging time schedule and the amount of charging. For example, the rates of electricity will be cheap at night or at specific scheme when time of use (TOU) is available, a coordinated charging strategy will schedule and optimize the EV charging time to fit in with the TOU or when demand is low. Authors in [24] present an intelligent strategy to control the EV charging time associated with TOU price. 
This proposed charging schedule is proved that to help reduce charging cost and flatten the load curve. Authors in [25] presents the linear programming (LP) method to optimize the charging rate for each $\mathrm{EV}$ in order to attain the maximization of the total charged power. Authors in [26] use a real-time smart load management (RT-SLM) method to minimize the total cost of energy generating associated with energy losses. The method incorporates the real-time electricity prices and EV owner's charging behaviour to reduce the generation cost.

Coordinated charging strategies are utilized with integration of solar photovoltaic (PV) energy [27]. The installation of a solar PV system on the EV home owners and at public charging station sites can eliminate the issues of the grid caused by high EV penetration [4], [6]. However, the PV power output fluctuates and is intermittent in nature. Thus, energy buffer units (EBU) using battery storage can be integrated to keep the continuous power supply to the connected loads. The integration of the EBU with the PV offers effective EV charging strategies [28].

\section{FUTURE TRENDS}

It is predicted that EV is the dominant means of future transportation as it benefits the environment; however, recently there is a weak penetration of EVs in Australia and worldwide. The main reason for this is the charging time and the long wait time ( $7-8$ hours) to get the car charged fully. Although home chargers and public chargers are now becoming more popular, but the charging time cannot be reduced easily due to the limitation of power ratings of the connection (13A for household sockets in Australia). The only feasible solution is to build fast charging stations (FCS), which can work as petrol station to allow the charging of an EV within a half of hour from its depletion. However, it is difficult to implement FCS widely as there is the need of an upgrade in the distribution grid as well. In addition, technology, codes and standards for FCS are immature and a huge investment is required to develop the system. In order to mitigate the effects of the FCS on the grid, renewable energy resources and an energy buffer unit (EBU) are usually integrated with FCS. The future of the FCS for public charging is shown in Fig. 7. Solar PV energy and an EBU are utilized to mitigate all grid issues caused of the pulse power from the fast charging. The energy can be exchanged between the grid, EV batteries, and the energy buffer unit. In normal operation, during daytime, the EV batteries can be charged from the solar PV with the support of EBU or other parked EVs if needed. In night-time, EV batteries can be charged from the grid with the support from EBU or other parked EVs. EVs also can support to the grid at the peak load demand if needed. By this way, the grid will never become unstable with a high pulse power of charging from EVs.

Recently, rooftop home PV systems become increasingly used in Australia, as it is considered environmentally friendly to have an EV that is charged from the PV solar energy at home. From this point of view, the idea to have a single power conditioning system from two systems is established. This causes the investment cost to reduce while increasing the system stability and less utilization of high power devices.

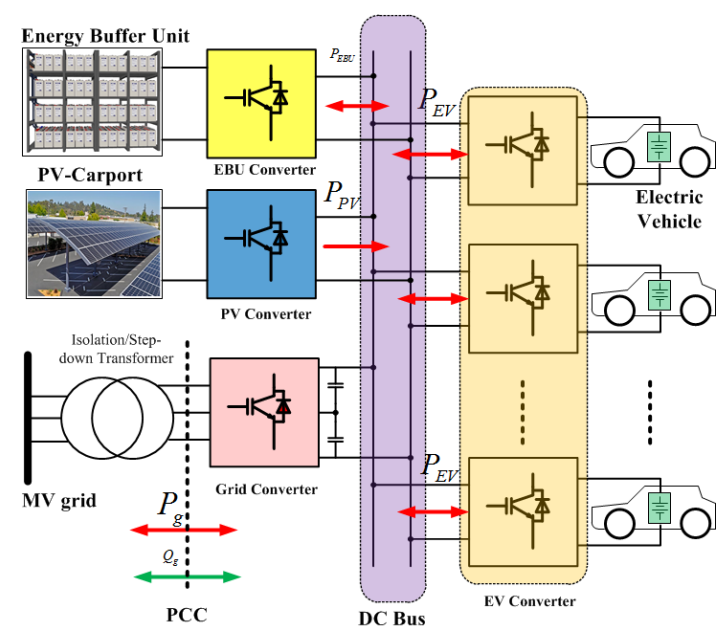

Fig. 7. Infrastructure of a future EV fast charging station.

Fig. 8 (a) shows the concept of a shared power conditioning board (SPCB) for a Home PV-EV system which controls the power exchange between PV energy, EV battery and the grid. It can be seen that, on-board chargers can be eliminated. The SPCB plays a key role in the system as it can maximize the power generation from solar PV, control charging/ discharging for EV batteries and control the grid interaction. A laboratory set up for the Home PV-EV system is showed in Fig. 8 (b) which is being studied by the researchers in the Australian Power Quality and Reliability Centre (APQRC) at the University of Wollongong. The SPCB has three converters for the PV-Maximum power point tracking (MPPT), EV battery charging/ discharging, and grid interactive control. The control algorithm is implemented using a Field Programmable Gate Array (FPGA), referred to as the General Purpose Inverter Control (GPIC) card from National Instruments.

The SPCB control algorithm was developed in order to ensure that the Home PV-EV system performs satisfactorily under the following scenarios:

1) The EV Battery is charged at high PV generation (mid-day).

2) Energy from PV is fed to the load and grid when the EV battery is fully charged

3) The EV battery injects power into the grid to shave the peak demand.

4) During islanding or stand-alone scenario when the main ac grid fails, the EV battery will now supply power to the home load.

Such a system will help to enhance the power quality of the overall grid system with high solar PV and EV penetration. 


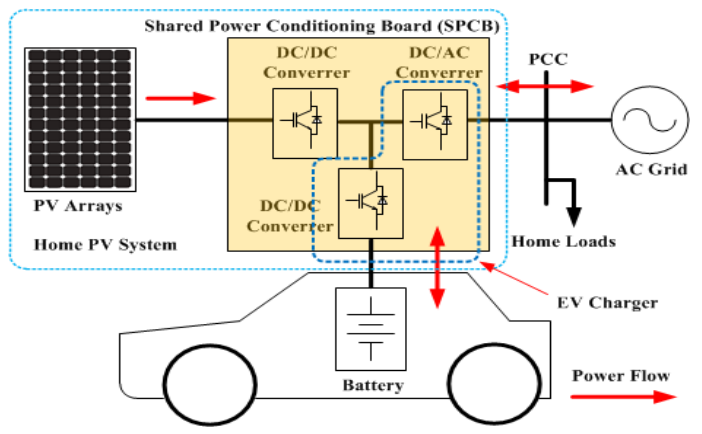

a)

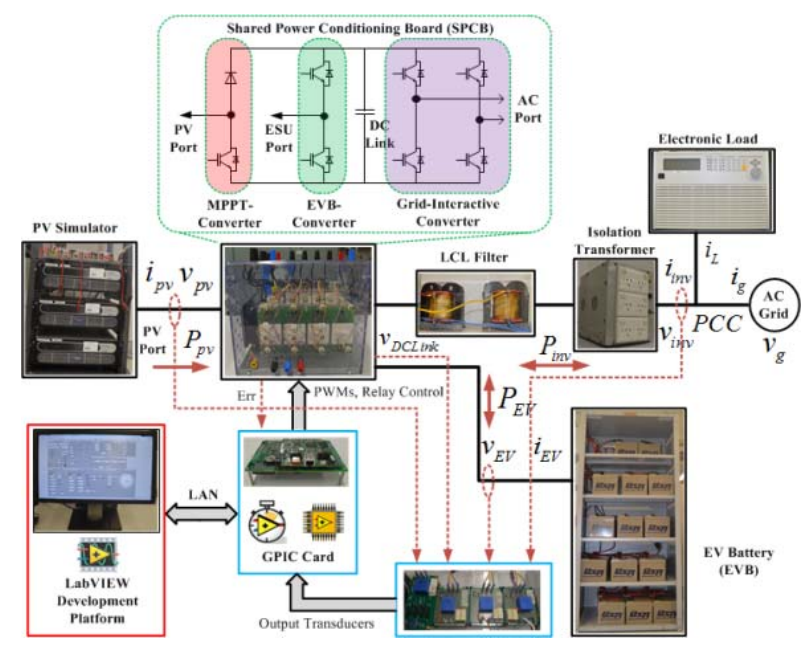

b)

Fig. 8. a) Recommendation of a Home PV-EV system, b) Home PV-EV system laboratory set-up.

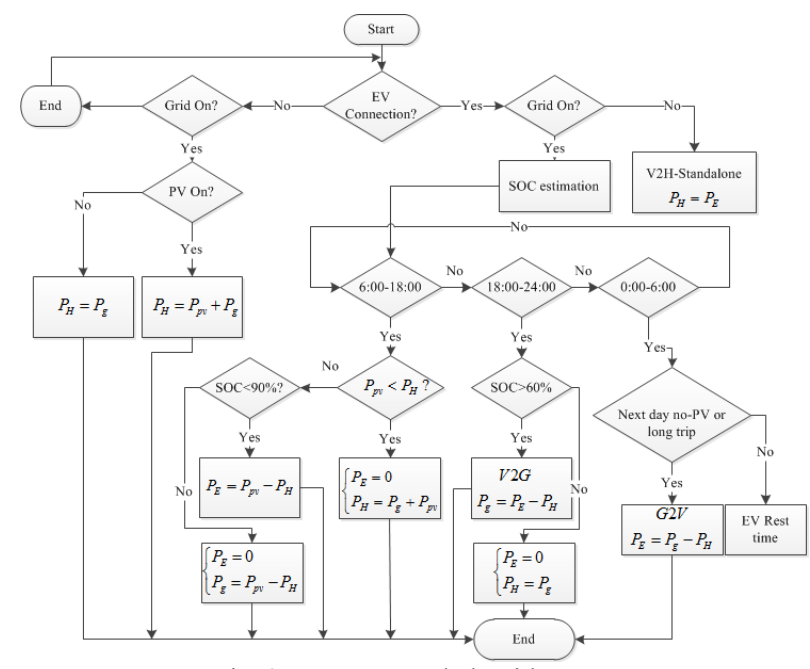

Fig. 9. Power control algorithm.

Fig. 9 shows the flow chart of the power control algorithm, where $P_{H}$ is home power or load, $P_{E}$ is the EV battery power, $P_{p v}$ is the PV power and $P_{g}$ is the grid power. Fig. 10 shows preliminary simulation results, which have been conducted using Matlab/ Simulink. At first, the home load and the EV are disconnected; and the total PV power generation is injected into the grid $(0-0.5 \mathrm{~s})$. A light load is connected at $0.5 \mathrm{~s}, P_{H}$ is less than $P_{p v}$, and then PV power supplies to the load and injects to the grid $(0.5 \mathrm{~s}-1 \mathrm{~s})$. The EV battery is plugged in and starts to charge at the rates such that its power and home load power are equal to total PV power generation. This results in zero power consumption from the grid $(1 \mathrm{~s}-1.5 \mathrm{~s})$. When a high load is connected and the grid needs a support, the EV battery will be discharged (1.5s$2.5 \mathrm{~s})$.

Fig. 11 shows the experimental results using the laboratory set-up as shown in Fig. 8 (b).

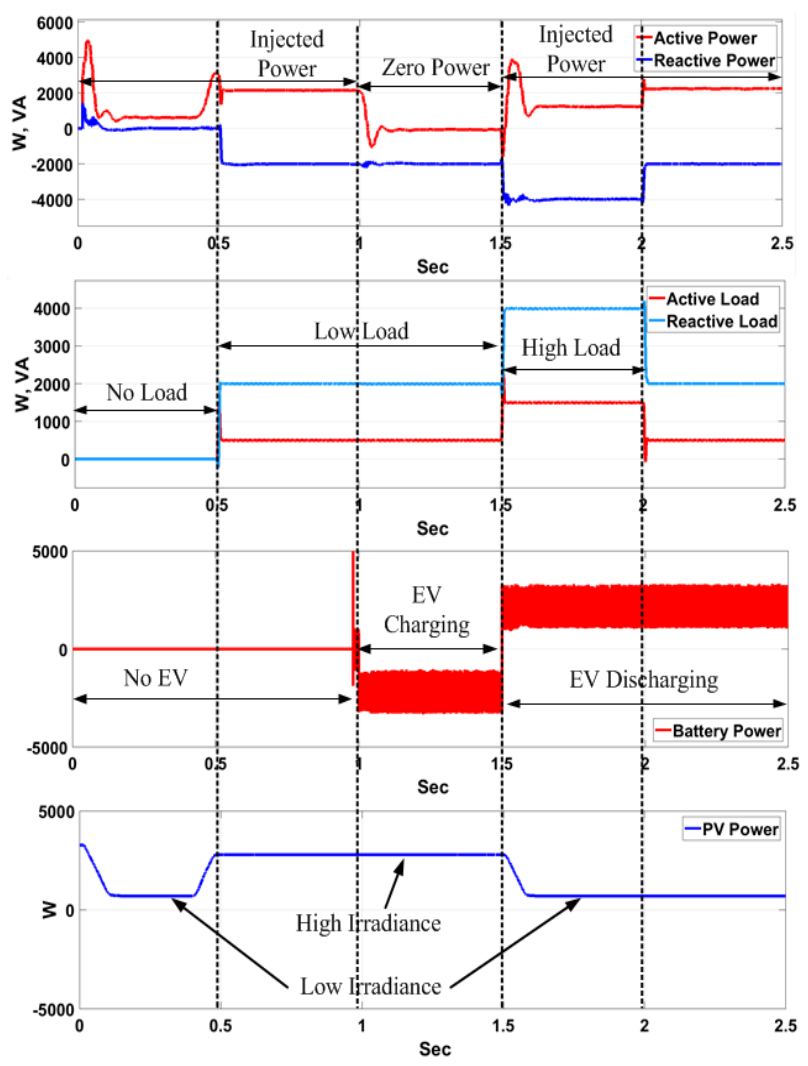

Fig. 10. Simulation results of Home PV-EV system.

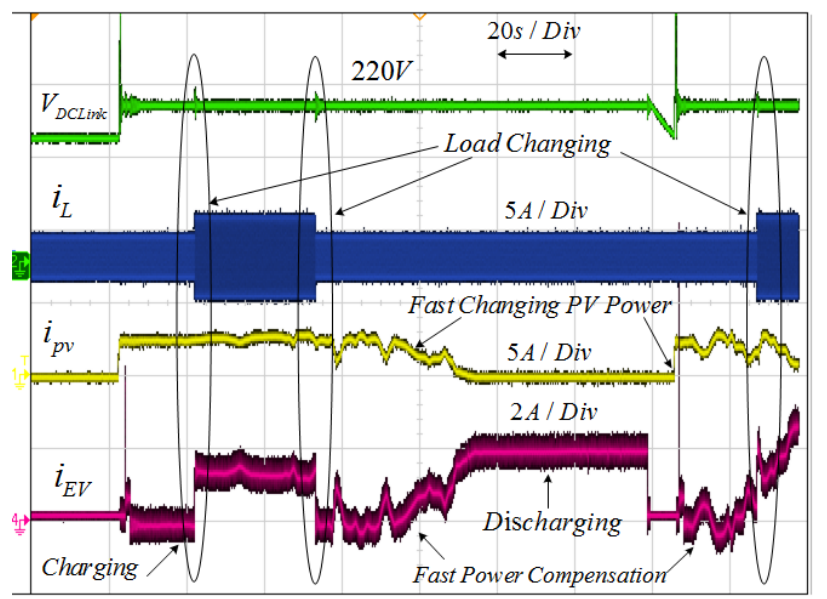

Fig. 11. Experimental results of Home PV-EV system. 


\section{CONCLUSIONS}

This paper reviewed the status quo of EV battery charging infrastructures. The selective typical topologies which are suitable candidates for each level of an EV charger have been presented. It can be seen that Level 1 and Level 2 charger topologies have only several options, which are based on basic DC/DC converters. Level 3 chargers are promising candidates for future EV high penetration as it can be implemented for FCS with full operation modes. The recent converters which are implemented for Level 3 chargers are multilevel converters which have a high power density. The silicon switching device is commonly used in the power stage of EV chargers; however, it will be replaced by wide bandgap silicon carbide ( $\mathrm{SiC}$ ) devices in order to attain a high efficiency, high power density and high switching frequency in power stages which will help reduce the charger's weight and volume.

The future of public charging stations and Home PV-EV charging systems are recommended, in which the integration of solar PV into FCS will provide the way forward. Home PV-EV with the SPCB is the best option for a home EV charger taking advantage of the home solar PV system.

\section{REFERENCES}

[1] I. E. Agency. Global EV Outlook 2016 [Online]. Available: https://www.iea.org/publications/freepublications/publication/Glo bal_EV_Outlook 2016.pdf

[2] M. Kesler, M. C. Kisacikoglu, and L. M. Tolbert, "Vehicle-toGrid Reactive Power Operation Using Plug-In Electric Vehicle Bidirectional Offboard Charger," IEEE Transactions on Industrial Electronics, vol. 61, pp. 6778-6784, 2014.

[3] N. Z. Xu and C. Y. Chung, "Reliability Evaluation of Distribution Systems Including Vehicle-to-Home and Vehicle-to-Grid," IEEE Trans. Power Syst., vol. 31, no. 1, pp. 759-768, Jan. 2016.

[4] M. Yilmaz and P. T. Krein, "Review of the Impact of Vehicle-toGrid Technologies on Distribution Systems and Utility Interfaces," IEEE Trans. Power Electron., vol. 28, no. 12, pp. 5673-5689, Dec. 2013.

[5] K. Clement-Nyns, E. Haesen, and J. Driesen, "The Impact of Charging Plug-In Hybrid Electric Vehicles on a Residential Distribution Grid," IEEE Transactions on Power Systems, vol. 25, pp. 371-380, 2010.

[6] U. C. Chukwu and S. M. Mahajan, "V2G Parking Lot With PV Rooftop for Capacity Enhancement of a Distribution System," IEEE Transactions on Sustainable Energy, vol. 5, pp. 119-127, 2014.

[7] S. International. SAE's J1772 'combo connector' for ac and dc charging advances with IEEE's help [Online]. Available: http://articles.sae.org/10128/

[8] CHAdeMO. What is CHAdeMO [Online]. Available: https://www.chademo.com/about-us/what-is-chademo/

[9] N. Tashakor, E. Farjah, and T. Ghanbari, "A Bidirectional Battery Charger With Modular Integrated Charge Equalization Circuit," IEEE Transactions on Power Electronics, vol. 32, pp. 2133-2145, 2017.

[10] V. Monteiro, J. G. Pinto, and J. L. Afonso, "Operation Modes for the Electric Vehicle in Smart Grids and Smart Homes: Present and Proposed Modes," IEEE Transactions on Vehicular Technology, vol. 65, pp. 1007-1020, 2016.

[11] M. C. Kisacikoglu, M. Kesler, and L. M. Tolbert, "Single-Phase On-Board Bidirectional PEV Charger for V2G Reactive Power
Operation," IEEE Transactions on Smart Grid, vol. 6, pp. 767$775,2015$.

[12] W. Haoyu, S. Dusmez, and A. Khaligh, "Design and Analysis of a Full-Bridge LLC-Based PEV Charger Optimized for Wide Battery Voltage Range," IEEE Transactions on Vehicular Technology, vol. 63, pp. 1603-1613, 2014.

[13] F. Musavi, M. Edington, W. Eberle, and W. G. Dunford, "Evaluation and Efficiency Comparison of Front End AC-DC Plug-in Hybrid Charger Topologies," IEEE Transactions on Smart Grid, vol. 3, pp. 413-421, 2012.

[14] C. Shi, H. Wang, S. Dusmez, and A. Khaligh, "A SiC-Based High-Efficiency Isolated Onboard PEV Charger With Ultrawide DC-Link Voltage Range," IEEE Transactions on Industry Applications, vol. 53, pp. 501-511, 2017.

[15] M. Restrepo, J. Morris, M. Kazerani, and C. Canizares, "Modeling and Testing of a Bidirectional Smart Charger for Distribution System EV Integration," IEEE Transactions on Smart Grid, pp. 1-1, 2016.

[16] D. S. Gautam, F. Musavi, M. Edington, W. Eberle, and W. G. Dunford, "An Automotive Onboard 3.3-kW Battery Charger for PHEV Application," IEEE Transactions on Vehicular Technology, vol. 61, pp. 3466-3474, 2012.

[17] J. Zhang, J.-S. Lai, R.-Y. Kim, and W. Yu, "High-Power Density Design of a Soft-Switching High-Power Bidirectional dc\&ndash;dc Converter," IEEE Transactions on Power Electronics, vol. 22, pp. 1145-1153, 2007.

[18] G. Buja, M. Bertoluzzo, and C. Fontana, "Reactive power compensation capabilities of V2G-enabled electric vehicles," IEEE Transactions on Power Electronics, pp. 1-1, 2017.

[19] L. Tan, B. Wu, V. Yaramasu, S. Rivera, and X. Guo, "Effective Voltage Balance Control for Bipolar-DC-Bus-Fed EV Charging Station With Three-Level DC-DC Fast Charger," IEEE Transactions on Industrial Electronics, vol. 63, pp. 4031-4041, 2016.

[20] S. Rivera and B. Wu, "Electric Vehicle Charging Station With an Energy Storage Stage for Split-DC Bus Voltage Balancing," IEEE Transactions on Power Electronics, vol. 32, pp. 2376-2386, 2017.

[21] M. J. E. Alam, K. M. Muttaqi, and D. Sutanto, "Effective Utilization of Available PEV Battery Capacity for Mitigation of Solar PV Impact and Grid Support With Integrated V2G Functionality," IEEE Transactions on Smart Grid, vol. 7, pp. $1562-1571,2016$

[22] L. W. a. M. A. Robert C. Green II, "The Impact of Plug-in Hybrid Electric Vehicles on Distribution Networks: a Review and Outlook," presented at the Proc. IEEE Power Energy Soc. Gen. Meeting, 2010.

[23] A. Dubey and S. Santoso, "Electric Vehicle Charging on Residential Distribution Systems: Impacts and Mitigations," IEEE Access, vol. 3, pp. 1871-1893, 2015.

[24] Y. Cao, S. Tang, C. Li, P. Zhang, Y. Tan, Z. Zhang, et al., "An Optimized EV Charging Model Considering TOU Price and SOC Curve," IEEE Transactions on Smart Grid, vol. 3, pp. 388-393, 2012.

[25] P. Richardson, D. Flynn, and A. Keane, "Optimal Charging of Electric Vehicles in Low-Voltage Distribution Systems," IEEE Trans. Power Syst., vol. 27, no. 1, pp. 268-279, Feb. 2012.

[26] S. Deilami, A. S. Masoum, P. S. Moses, and M. A. S. Masoum, "Real-Time Coordination of Plug-In Electric Vehicle Charging in Smart Grids to Minimize Power Losses and Improve Voltage Profile," IEEE Trans. Smart Grid, vol. 2, no. 3, pp. 456-467, Sept. 2011.

[27] J. M. Foster, G. Trevino, M. Kuss, and M. C. Caramanis, "Plug-In Electric Vehicle and Voltage Support for Distributed Solar: Theory and Application," IEEE Systems Journal, vol. 7, pp. 881888, 2013.

[28] M. O. Badawy and Y. Sozer, "Power Flow Management of a Grid Tied PV-Battery System for Electric Vehicles Charging," IEEE Trans. Ind. Appl., vol. 53, no. 2, pp. 1347-1357, Mar. 2017. 